\title{
Therapeutic Efficacy of 1,927-nm Fractionated Thulium Laser Energy and Polydeoxyribonucleotide on Pattern Hair Loss
}

\author{
Sung Bin Cho ${ }^{1,2}$ \\ Zhenlong Zheng 3,4 \\ Jin-Soo Kang ${ }^{2}$ \\ Heesu Kim ${ }^{1}$
}

\begin{abstract}
${ }^{1}$ Department of Dermatology, International St. Mary's Hospital, Catholic Kwandong University College of Medicine, Incheon, Korea ${ }^{2}$ Kangskin Dermatology Clinic, Seoul, Korea ${ }^{3}$ Department of Dermatology and Cutaneous Biology Research Institute, Yonsei University College of Medicine, Seoul, Korea ${ }^{4}$ Department of Dermatology, Yanbian University Hospital, Yanji, China
\end{abstract}

Received March 28, 2016

Accepted April 21, 2016

\author{
Correspondence \\ Heesu Kim \\ Department of Dermatology, International St. \\ Mary's Hospital, Catholic Kwandong University \\ College of Medicine, Simgok-ro 100gil 25, Seo-gu, \\ Incheon 22711, Korea \\ Tel: +82-32-290-3141 \\ Fax: +82-32-290-3142 \\ E-mail: yollikimagmail.com \\ (C) Korean Society for Laser Medicine and Surgery \\ (c) This is an open access article distributed under the \\ terms of the Creative Commons Attribution Non- \\ Commercial License (http://creativecommons.org/ \\ licenses/by-nc/4.0) which permits unrestricted non- \\ commercial use, distribution, and reproduction in any \\ medium, provided the original work is properly cited.
}

\author{
Background and Objectives \\ Intra-perifollicular polydeoxyribonucleotide (PDRN) injections result in \\ clinical improvements in hair thickness and density in patients with \\ pattern hair loss (PHL). The objective of this study is to evaluate the \\ efficacy of combined treatment with a 1,927-nm fractionated thulium \\ laser and PDRN injections for treatment of PHL.
}

\section{Materials and Methods}

We compared clinical outcomes in eight PHL patients treated with 12 sessions of combined treatment with thulium laser and PDRN injections to those in another eight PHL patients treated with 12 sessions of mesotherapy and PDRN injections.

\section{Results}

One week after the final treatment session, patients treated with the thulium laser and PDRN showed clinical improvements in mean hair counts $(20.4 \pm 15.7 \% ; p=0.005)$ and mean hair thickness $(53.1 \pm 31.1 \%$; $p<0.001$ ), compared to baseline values. Patients treated with mesotherapy and PDRN also showed clinical improvements in mean hair counts (9.7 $\pm 7.4 \% ; p=0.007)$ and mean hair thickness (16.1 $\pm 25 \%$; $p>0.05$ ). Further statistical analysis showed that combined treatment with the thulium laser and PDRN injections resulted in greater improvement in hair thickness $(p=0.029)$ than combined application of mesotherapy and PDRN, but not in hair counts ( $p>0.05)$.

\section{Conclusion}

Use of thulium laser energy in combination with PDRN injections for treatment of PHL results in remarkable improvements in hair thickness and density.

\section{Key words}

Pattern hair loss; Thulium laser; Polydeoxyribonucleotide; Mesotherapy 


\section{INTRODUCTION}

Theoretically, restoration of hair counts and thickness in patients with pattern hair loss (PHL) can be achieved by promoting cellular proliferation and differentiation of follicular progenitor cells during hair growth cycles. ${ }^{1}$ Current strategies for treating PHL seek to stimulate antiapoptotic regulators and improve factors important to the health of hair follicles, particularly vascular components. ${ }^{1}$ To do so, along with oral medications of finasteride or dutasteride, topical agents of minoxidil and alfatradiol, and hair transplantation, injections of tissue activators, anti-oxidants, and autologous platelet-rich plasma concentrations have also been used to treat $\mathrm{PHL} .^{1-7} \mathrm{Com}-$ monly used tissue activators and anti-oxidants in PHL patients include polydeoxyribonucleotide (PDRN), placental extracts, zinc sulfate, biotin, and nicotinamide. ${ }^{6,7}$

Laser/light-based devices have also been utilized as additional or alternative treatment modalities for treating PHL, alopecia areata, and scarring alopecia. These devices have been shown to improve blood supply to hair follicles and to up-regulate expression of signaling molecules and growth factors. ${ }^{8-10}$ In the literature, low-level laser/light, non-ablative erbium:glass fractionated laser, and ablative carbon dioxide fractionated laser therapies are described as generating various clinical outcomes with no remarkable major side effects. ${ }^{8-11}$

In this study, we aimed to evaluate the efficacy of combined treatment with 1,927-nm fractionated thulium laser energy and intra-perifollicular PDRN injections in treating PHL. To do so, we compared clinical outcomes for the combined treatment with those for combined treatment with mesotherapy and PDRN injections.

\section{MATERIALS AND METHODS}

\section{Patients and treatment protocol}

A total of 16 Korean patients $(12$ males and 4 females; mean age: 33.1 years; age range: $26-46$ years) with $\mathrm{PHL}$ were enrolled in this study. Diagnosis of PHL was made by physical examination and phototrichograms to evaluate the clinical features of miniaturized terminal hairs and/or a reduced numbers of hairs with negative hair pull tests. In this study, we excluded patients who had been treated for PHL with topical and oral medications, including minoxidil, alfatradiol, prostaglandin analogues, finasteride, dutasteride, and anti-androgens; mesotherapy and intra-perifollicular injection therapy; laser/light-based therapy, including fractionated laser treatment and lowlevel light therapy; intra-perifollicular platelet-rich plasma preparation injection; and hair transplantation within the preceding six months. This study was approved by the Institutional Review Board of International St. Mary's Hospital, Catholic Kwandong University, College of Medicine, Incheon, Korea.

After obtaining written informed consent, eight patients (mean age: 35.1 years; age range: 29-46 years) were randomly selected to receive 12 sessions of 1,927-nm fractionated thulium laser treatment (LASEMD ${ }^{\text {TM}}$; Lutronic Corp., Goyang, Koreal in combination with intra-perifollicular injections of PDRN (Placentex ${ }^{\circledR}$ integro; Mastelli Ltd., Sanremo, Italy) at weekly intervals. In each session,
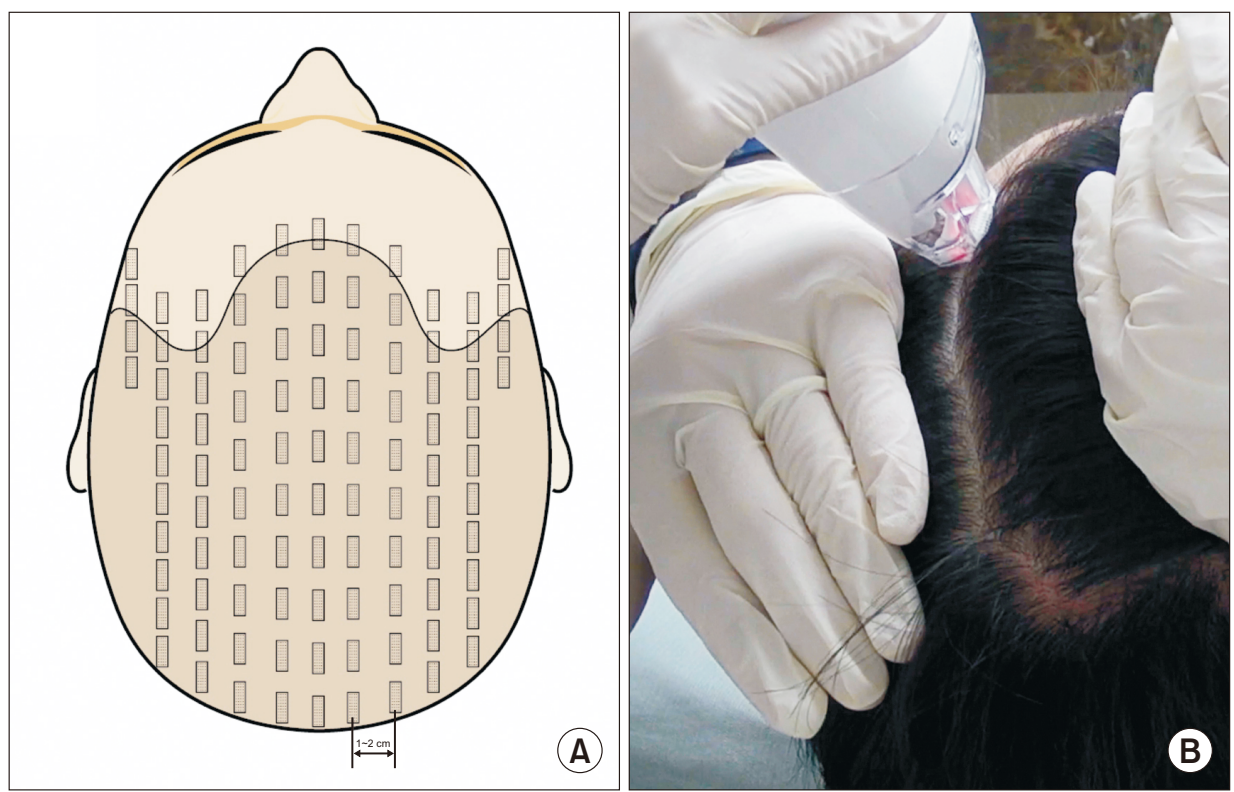

Fig. 1. (A) Schematic view of 1,927$\mathrm{nm}$ fractionated thulium laser treatment on the frontal, mid, and vertex areas of the scalp. Each square demonstrates a laser pulse containing 40 fractionated thermal injury zones over an area of about $10 \mathrm{~mm} \times 4 \mathrm{~mm}$. (B) Representative photograph of delivering thulium laser treatment to the interfollicular scalp in a patient with pattern hair loss. 
the scalp was first cleansed with 70\% ethanol, and then, a total of 100-140 shot counts of thulium laser energy was delivered to frontal, mid, and vertex areas of the scalp at a power of $5 \mathrm{~W}$ and an energy of $6 \mathrm{~mJ}$ under a static operating mode (Fig. 1). Each pulse generated 40 fractionated zones of thermal injury over an area of about $10 \mathrm{~mm} \times 4$ $\mathrm{mm}$ along the scalp; the diameter of each individual thermal injury zone was about $100 \mu \mathrm{m}$. Next, $2 \mathrm{ml}$ of PDRN was injected into the deep dermis along the frontal, mid, and vertex areas. Immediately after the treatment, a 3-mL mixture of $\mathrm{d}$-panthenol $(250 \mathrm{mg} / \mathrm{ml})$, nicotinamide $(20$ $\mathrm{mg} / \mathrm{ml})$, riboflavin $(2 \mathrm{mg} / \mathrm{ml})$, biotin $(250 \mu \mathrm{g} / \mathrm{ml})$, and zinc sulfate $(1 \mathrm{mg} / \mathrm{ml})$ were applied topically to the scalp.

The other eight randomly selected patients (mean age: 31.1 years; age range: $26-38$ years) were treated with 12 sessions of mesotherapy and intra-perifollicular PDRN injections at weekly intervals. After cleansing the scalp, mesotherapy injections were administered by injecting the 3 -ml mixture of $d$-panthenol, nicotinamide, riboflavin, biotin, and zinc sulfate, all of which are approved for intramuscular and/or intravenous injection, into the scalp using an automated injector at a penetrating needle depth of $2.0-2.5 \mathrm{~mm}$. Thereafter, $2 \mathrm{ml}$ of PDRN was injected into the deep dermis. All procedures were performed without local anesthesia. Patients were advised to refrain from applying other treatment modalities for PHL during the course of treatment and follow-up.

\section{Objective evaluation and statistical analysis}

As described in a previous report, ${ }^{6,7}$ digital images of the scalp and hairs were captured at $1 \times$ and 40x magnification using a computerized, hand-held USB camera PT system (Follioscope ${ }^{\circledR}$; LeedM Corporation, Seoul, Koreal for objective evaluation at baseline and at one week after the final treatment. The lens of the camera was positioned at the " $V$ " point along the vertex of the scalp, where the mid-sagittal and coronal planes intersected. ${ }^{6,7}$ Thereafter, relative values for hair counts and thickness
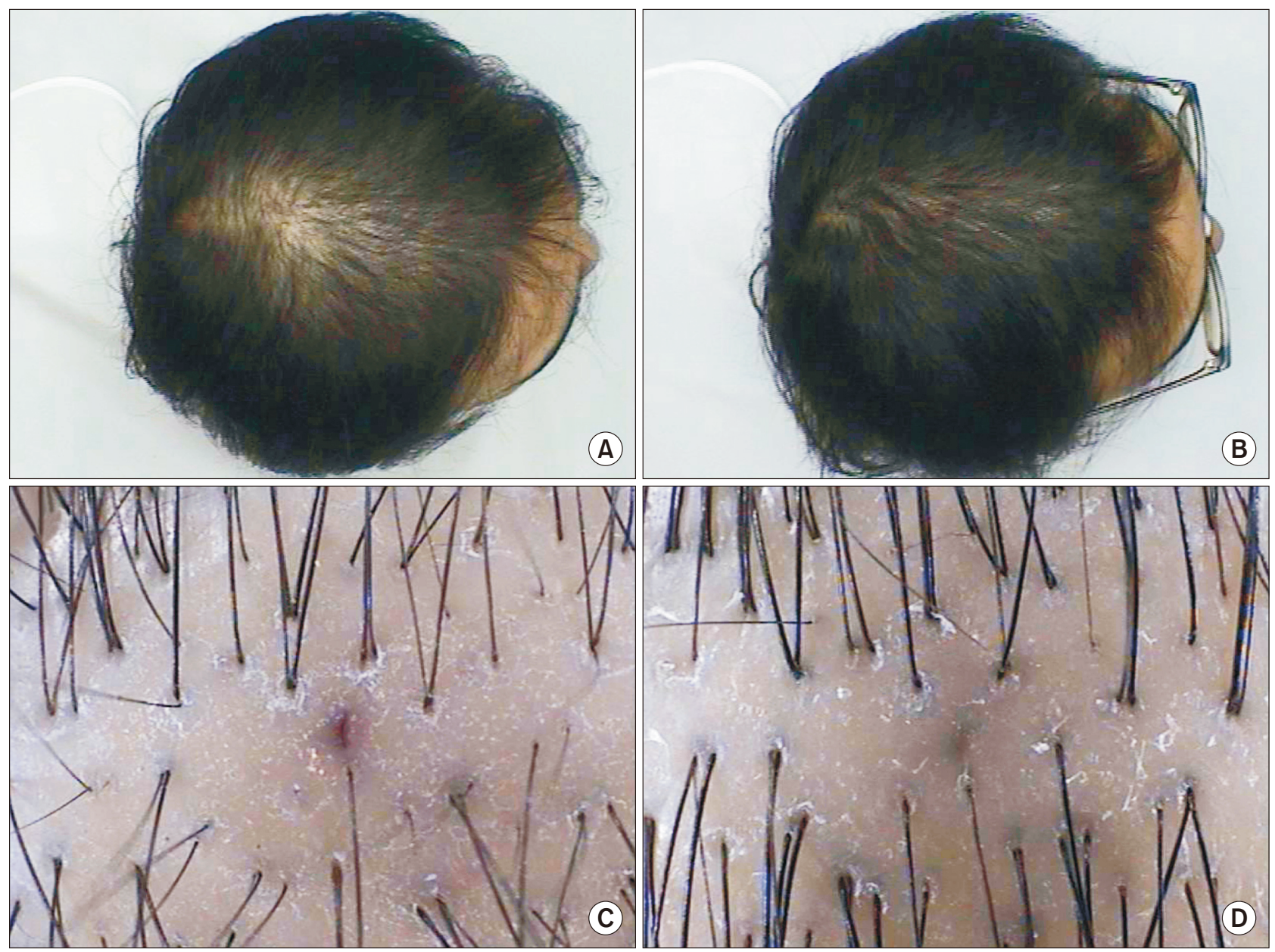

Fig. 2. Digital images of hairs at the "V" point in patient 1 , group 1 with PHL (A, C) before and (B, D) at one week after the last session of treatment with the thulium laser and intra-perifollicular PDRN injections. Original magnification $(A, B) \times 1$ and $(C, D) \times 40$. 
were measured with the ANALYZE and MEASURE plugins in Image J software, version 1.50 (National Institutes of Health, Bethesda, MD, USA). Also, at each treatment session and at one week after the last treatment session, PHL patients were surveyed for any side effects that could be associated with the treatment, including intolerable pain, scalp redness and edema, oozing, bleeding, scaling or crusting, or remarkable hair loss.

A normality test was performed for clinical and laboratory data using a Kolmogorov-Smirnov test, and then, the results were analyzed by paired $t$-test and linear mixed models (MIXED) with Bonferroni post hoc analysis for parametric criteria using SAS software, version 9.2 (SAS Institute Inc., Cary, NC, USA). Differences with $p$-values of less than 0.05 were considered statistically significant.

\section{RESULTS}

At baseline, no statistical differences in patient age $(p>0.05)$ and number of hairs ( $p>0.05)$ were noted between the thulium laser and PDRN treatment group (group 1) and the mesotherapy and PDRN treatment group Igroup 2). Baseline hair thickness, however, was significantly thinner in group 1 ( $p=0.041)$. At one week after the final treatment session, patients in group 1 exhibited clinical improvements in both mean hair counts $(20.4 \pm 15.7 \%$; $p=0.005)$ and mean hair thickness (53.1 $\pm 31.1 \% ; p<0.001$ ), compared to baseline values (Fig. 2, 3). Patients in group 2 also showed clinical improvements in mean hair counts $(9.7 \pm 7.4 \% ; p=0.007)$ and mean hair thickness (16.1 $\pm 25 \%$; $p>0.05$ ), compared to baseline values (Fig. 4). At one week after the final treatment session, hair counts and hair thickness were similar between groups 1 and 2 l $p>0.05$ for both) (Fig. 5). Meanwhile, in MIXED analysis, combined
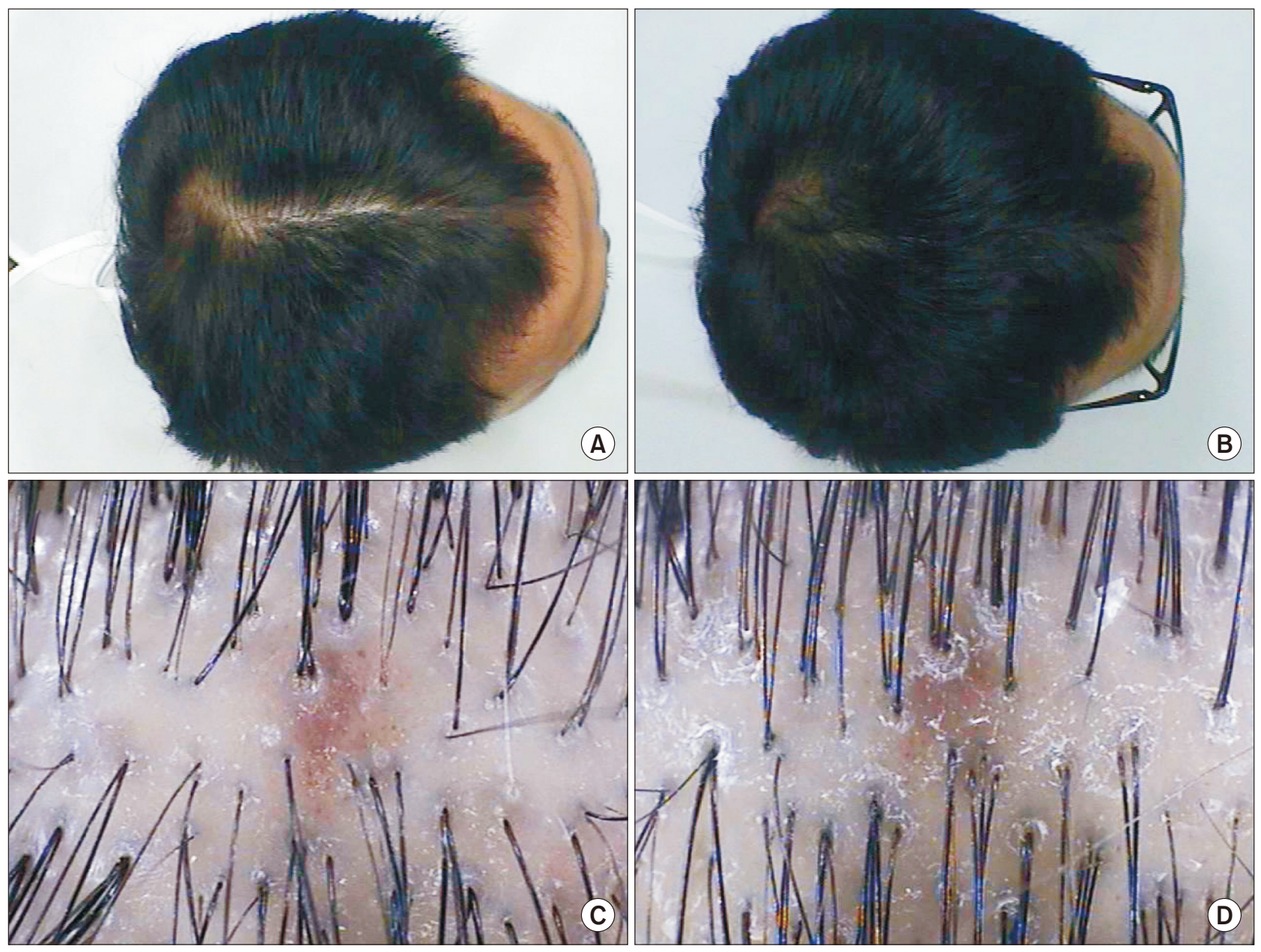

Fig. 3. Digital images of hairs at the "V" point in patient 5, group 1 with PHL (A, C) before and (B, D) at one week after the last session of treatment with the thulium laser and intra-perifollicular PDRN injections. Original magnification $(A, B) \times 1$ and $(C, D) \times 40$. 
treatment with thulium laser energy and PDRN injections was found to have generated greater improvement in hair thickness ( $p=0.029$ ) than mesotherapy and PDRN injections, but not in hair counts ( $p>0.05$ ) (Table 1).

Generally, the procedure time for the thulium laser treatment was roughly 5 minutes or less, whereas that for the mesotherapy injections in group 2 was 10 minutes or less. In regards to side effects, all eight patients in group 1 reported well-tolerable pain during the laser treatment, and post-laser treatment redness was transient. Except for mild itching sensations and desquamation in one patient (12.5\%), no other side effects were recorded. In group 2, marked bleeding and oozing was observed around injection sites during mesotherapy. Four of the 8 patients treated with mesotherapy reported pain during the procedure that was sometimes intolerable $(N=4 ; 50 \%)$; itching sensations and desquamation were also observed ( $N=3 ; 37.5 \%)$. No other possible side ef- fects, including progression of PHL, temporary or longlasting alopecia areata or telogen effluvium, secondary bacterial, typical or atypical mycobacterial, viral, or fungal infections, and post-therapy scarring, were reported in any of the $16 \mathrm{PHL}$ patients.

\section{DISCUSSION}

In the present study, we found that combined treatment with thulium laser energy and PDRN intra-perifollicular injections generates significant clinical improvements in hair density and diameter, compared to combined treatment with mesotherapy and PDRN injections.

The laser device used in this study emitted laser energy at a wavelength of $1,927 \mathrm{~nm}$, which is better absorbed by water than non-ablative 1,540 -nm or 1,550$\mathrm{nm}$ erbium:glass laser energy, but less than ablative 10,600-nm carbon dioxide laser energy. ${ }^{11}$ By controlling
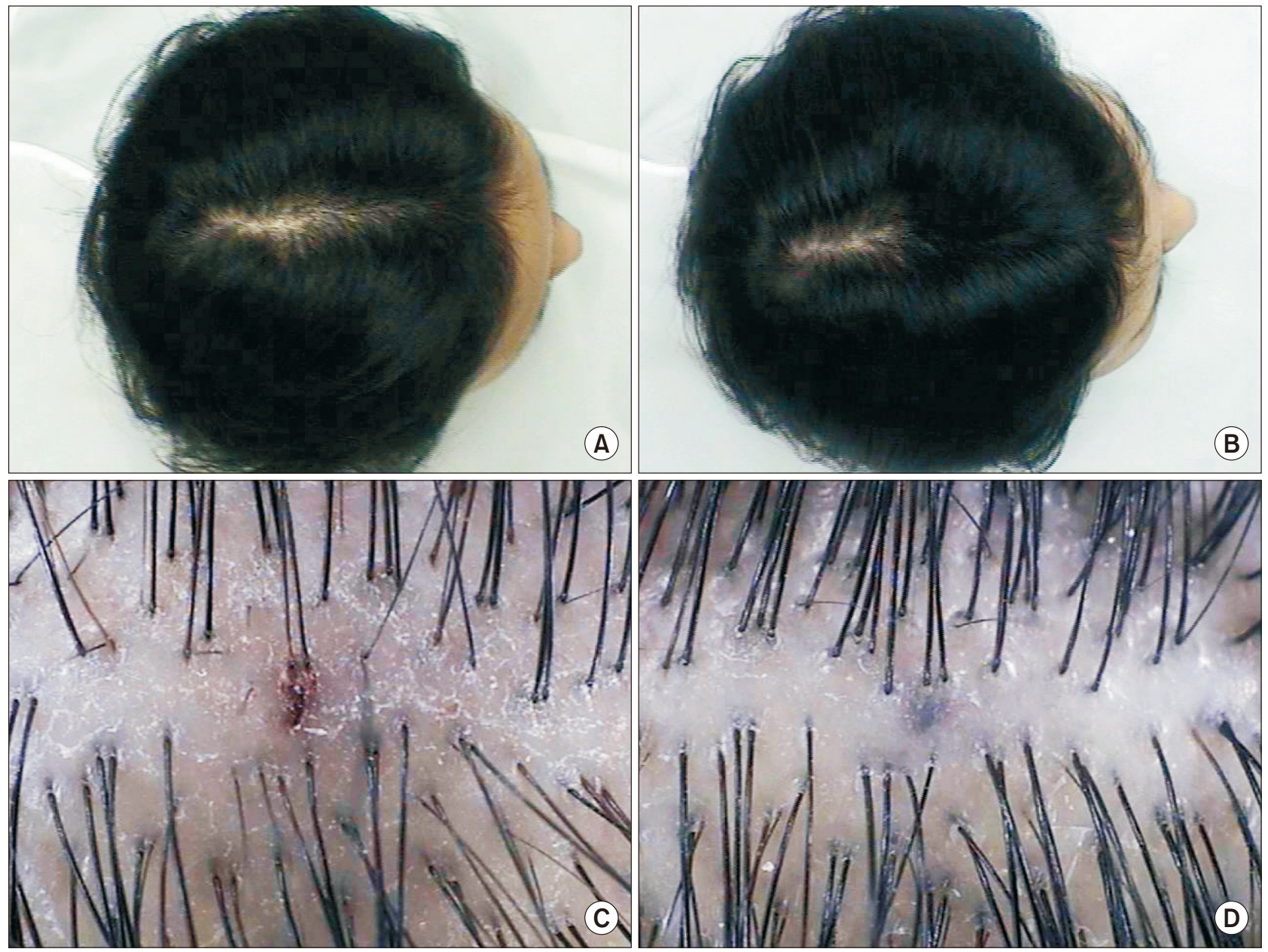

Fig. 4. Digital images of hairs at the "V" point in patient 1, group 2 with PHL (A, C) before and (B, D) at one week after the last session of treatment with mesotherapy and intra-perifollicular PDRN injections. Original magnification $(A, B) \times 1$ and $(C, D) \times 40$. 
A
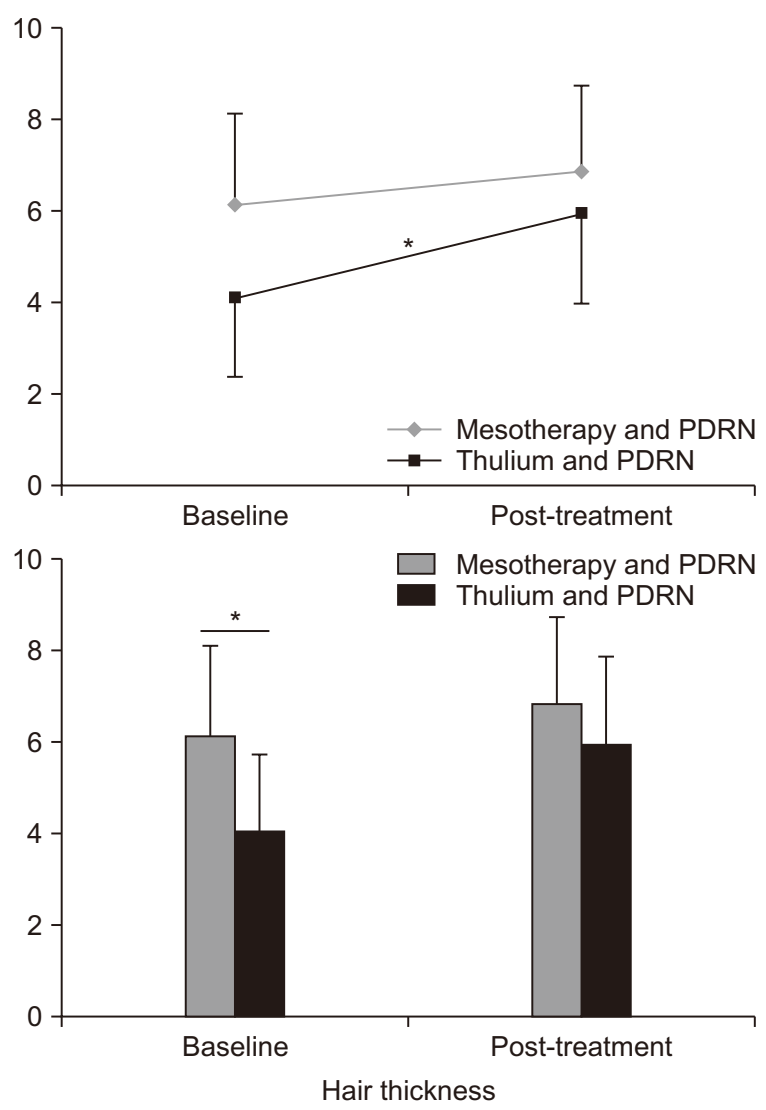

B
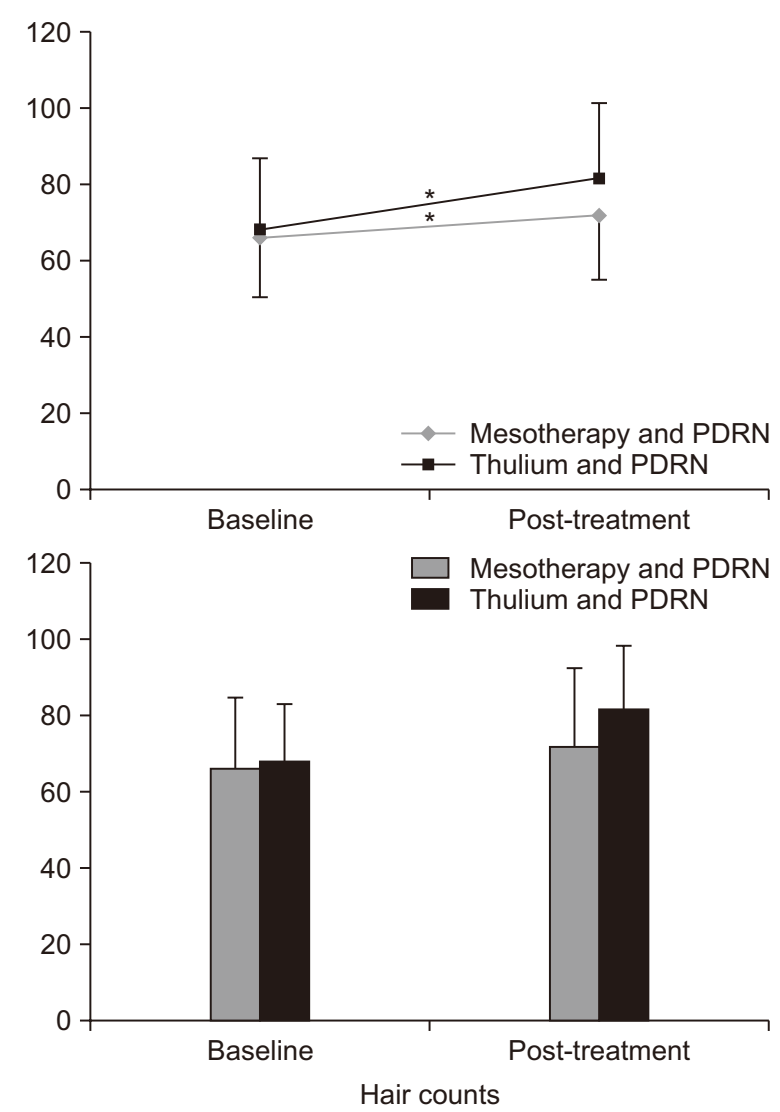

Fig. 5. Computerized phototrichogram analyses of (A) hair thickness and (B) counts in patients with pattern hair loss after combined treatment with the thulium laser and intra-perifollicular PDRN injections or mesotherapy and intra-perifollicular PDRN injections. ${ }^{*} p<0.05$.

Table 1. Comparison of combined treatment with a 1,927-nm fractionated thulium laser and polydeoxyribonucleotide injections (PDRN) and combined treatment with mesotherapy and PDRN injections

\begin{tabular}{|c|c|c|c|c|c|}
\hline & \multirow{2}{*}{ Mesotherapy and PDRN* } & \multirow{2}{*}{ Thulium laser and PDRN* } & \multicolumn{3}{|c|}{$p$-value } \\
\hline & & & Group & Time & Group x time \\
\hline \multicolumn{6}{|l|}{ Hair thickness } \\
\hline Baseline & $6.113 \pm 1.997$ & $4.038 \pm 1.678$ & $p=0.117$ & $p<0.001$ & $p=0.029$ \\
\hline Post-treatment & $6.863 \pm 1.852$ & $5.906 \pm 1.946$ & & & \\
\hline \multicolumn{6}{|l|}{ Hair counts } \\
\hline Baseline & $65.75 \pm 19.077$ & $67.875 \pm 15.16$ & $p>0.05$ & $p<0.001$ & $p>0.05$ \\
\hline Post-treatment & $72 \pm 20.256$ & $80.875 \pm 16.924$ & & & \\
\hline
\end{tabular}

*Data are presented as an estimated mean \pm standard deviation.

the energy and power of thulium laser energy, clinicians can limit the penetration depth of the laser and the degree of selective photothermolysis in the skin. In thulium laser treatments at a power of $5 \mathrm{~W}$ and an energy level of $3 \mathrm{~mJ}$, laser-induced tissue coagulation is limited to the epidermis and uppermost dermal tissues, whereas at a power of $5 \mathrm{~W}$ and an energy level of $20 \mathrm{~mJ}$, well-defined coagulated columns can be observed extending from the epidermis through the upper dermis (unpublished data). However, in our experience, thulium laser treatment at a power of $5 \mathrm{~W}$ and an energy level of $20 \mathrm{~mJ}$ can burn hair shafts. Accordingly, laser settings should be properly set to avoid excessive damage to the hair shafts and scalp.

In the present study, a power of $5 \mathrm{~W}$ and an energy of 6 $\mathrm{mJ}$ were used to induce laser-tissue interactions in the entire epidermis and the upper dermis. The laser-induced 
thermal reactions were generated in an attempt to stimulate follicular stem cells or progenitor cells to proliferate and differentiate into follicular cells. Indeed, a sufficient wound stimulus has been found to induce regeneration of epithelial cells into hair follicles through Wnt-dependent hair follicle neogenesis. ${ }^{12}$

In addition to the above, we suggest that the thulium laser-induced tissue reactions may have also provided effective routes for transdermal drug delivery of the PDRN and the $3-\mathrm{ml}$ mixture of $\mathrm{d}$-panthenol, nicotinamide, riboflavin, biotin, and zinc sulfate, which are commonly used as tissue activators and anti-oxidants to treat PHL patients. While the mesotherapy injections also facilitated effectively delivery of these therapeutic agents into the epidermis and upper dermis, topical application of the 3-ml mixture after thulium laser treatment resulted in more pronounced clinical improvements. Additionally, performing the thulium laser procedure took less time and was more convenient; moreover, there was no posttherapy oozing or bleeding.

In this study, we used PDRN as a tissue activator for treating PHL in combination with the thulium laser treatment or mesotherapy. Our study group previously reported that repetitive intra-perifollicular injections of PDRN results in significant improvements in hair counts and thickness in female patients with PHL. ${ }^{7}$ In review of our present results, we suggest that PDRN stimulates wound healing after thulium laser treatment, alleviates the potential side effects of laser therapy, and promotes hair follicle restoration.

In the present study, combined treatment with a thulium laser device and PDRN intra-perifollicular injections resulted in significantly greater clinical improvements in hair density and diameter than combined treatment with mesotherapy and PDRN injections. As well, performing the thulium laser procedure was quicker, more convenient, and generated fewer side effects than administering mesotherapy injections. Nevertheless, further investigations are required to evaluate the therapeutic effects of thulium laser alone for treating PHL.

\section{ACKNOWLEDGMENTS}

We would like to thank Hye Sun Lee, PhD (Department of Biostatistics, Yonsei University College of Medicine, Seoul, Koreal for her help with the statistical analyses.
Also, we would like to thank Anthony Thomas Milliken, ELS, at Editing Synthase (http://editingsynthase.com) for his help with the editing of this manuscript.

\section{REFERENCES}

1. Semalty M, Semalty A, Joshi GP, Rawat MS. Hair growth and rejuvenation: an overview. J Dermatolog Treat 2011;22:123-32.

2. Atanaskova Mesinkovska N, Bergfeld WF. Hair: what is new in diagnosis and management? Female pattern hair loss update: diagnosis and treatment. Dermatol Clin 2013;31:119-27.

3. Takikawa M, Nakamura S, Nakamura S, Ishirara M, Kishimoto S, Sasaki K, et al. Enhanced effect of platelet-rich plasma containing a new carrier on hair growth. Dermatol Surg 2011;37:1721-9.

4. Li ZJ, Choi HI, Choi DK, Sohn KC, Im M, Seo YJ, et al. Autologous platelet-rich plasma: a potential therapeutic tool for promoting hair growth. Dermatol Surg 2012;38:1040-6.

5. Park KY, Kim HK, Kim BJ, Kim MN. Letter: Platelet-rich plasma for treating male pattern baldness. Dermatol Surg 2012;38:2042-4.

6. Kang JS, Zheng Z, Choi MJ, Lee SH, Kim DY, Cho SB. The effect of CD34+ cell-containing autologous platelet-rich plasma injection on pattern hair loss: a preliminary study. J Eur Acad Dermatol Venereol 2014;28:72-9.

7. Lee SH, Zheng Z, Kang JS, Kim DY, Oh SH, Cho SB. Therapeutic efficacy of autologous platelet-rich plasma and polydeoxyribonucleotide on female pattern hair loss. Wound Repair Regen 2015;23:30-6.

8. Yoo KH, Kim MN, Kim BJ, Kim CW. Treatment of alopecia areata with fractional photothermolysis laser. Int J Dermatol 2010;49:845-7.

9. Lee GY, Lee SJ, Kim WS. The effect of a $1550 \mathrm{~nm}$ fractional erbium-glass laser in female pattern hair loss. J Eur Acad Dermatol Venereol 2011;25:1450-4.

10. Kim WS, Lee HI, Lee JW, Lim YY, Lee SJ, Kim BJ, et al. Fractional photothermolysis laser treatment of male pattern hair loss. Dermatol Surg 2011;37:41-51.

11. Cho S, Choi MJ, Zheng Z, Goo B, Kim DY, Cho SB. Clinical effects of non-ablative and ablative fractional lasers on various hair disorders: a case series of 17 patients. J Cosmet Laser Ther 2013;15:74-9.

12. Ito M, Yang Z, Andl T, Cui C, Kim N, Millar SE, et al. Wntdependent de novo hair follicle regeneration in adult mouse skin after wounding. Nature 2007;447:316-20. 